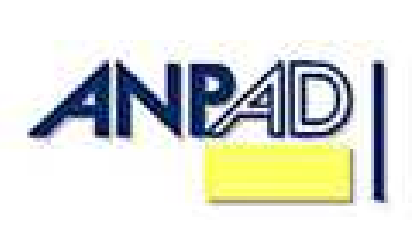

Disponível em

http://www.anpad.org.br/rac

RAC, Rio de Janeiro, v. 17, n. 1, art. 2,

pp. 18-41, Jan./Fev. 2013

(cc) EY-NC

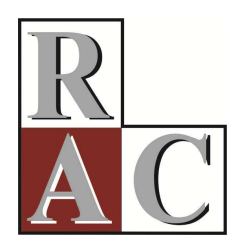

\title{
Instituições de Suporte, Serviços e Desempenho: um Estudo em Aglomeração Turística de Santa Catarina
}

\author{
Support Instittutions, Services and Performance in a \\ Southern Brazil Tourism Cluster
}

\author{
Valmir Emil Hoffmann * \\ E-mail: ehoffmann@unb.br \\ Universidade de Brasília - PPGA/UnB \\ Brasília, DF, Brasil. \\ Lucila Maria de Souza Campos \\ E-mail: lucila@deps.ufsc.br \\ Universidade Federal de Santa Catarina - DEPS/UFSC \\ Florianópolis, SC, Brasil.
}

* Endereço: Valmir Emil Hoffmann

Universidade de Brasília, Campus Darcy Ribeiro, PPGA - Instituto Central de Ciências, Ala Norte, Subsolo, Módulo 25, Brasília/DF, 70910-900.

Artigo recebido em 18.11.2011. Última versão recebida em 06.11.2012. Aprovado em 09.11.2012. 


\title{
Resumo
}

Este estudo teve por objetivo avaliar as instituições de suporte à atividade turística em destinos turísticos na região do litoral norte de Santa Catarina. A partir de uma discussão sobre as aglomerações territoriais, os recursos competitivos e o papel das instituições de suporte, foi realizada uma pesquisa com instituições de sete cidades da chamada Costa Verde e Mar naquele estado, que, além da localização próxima, têm em comum possuir o turismo de sol e praia entre suas principais atividades econômicas. A escolha por essa atividade econômica se deu pelo fato de que as empresas turísticas, de modo geral, aglomeram-se em torno dos atrativos turísticos. Desta forma, propiciam o surgimento de instituições de suporte à sua atividade, sobretudo pela facilidade de escala desses serviços. Os dados primários foram coletados por meio de um questionário com perguntas abertas e fechadas, aplicado aos dirigentes das instituições pesquisadas. Os dados secundários, relacionados ao desempenho turístico das cidades, foram retirados de uma página oficial do órgão de turismo estadual. O tratamento se deu por estatística descritiva inferencial e categorização. Os resultados apontam que há diversidade de instituições na região, mas que isso não se reflete em diversidade de serviços que se concentram nas assessorias.

Palavras-chave: aglomerações turísticas; instituições de suporte; instituições públicas; competitividade.

\begin{abstract}
The objective of this study was to evaluate clusters of tourism support institutions on the northern coast of the Brazilian state of Santa Catarina state. Based upon a discussion about clusters, competitive resources and support institutions role, research was undertaken in seven cities from the area called the Green Sea Coast. The chosen cities all have beach tourism as their primary economic activities. Touristic firms generally cluster close to tourist attractions, and thus create conditions for support institutions, especially in terms of economy of scale. We applied a survey, with both open and closed-ended question, to managers from the tourist agencies in order to gather primary data. Secondary data (related to tourism statistics) came from Santa Catarina's official state tourism institution. The data was treated using descriptive inferential and categorization statistics. Results point out that there a variety of institutions in the region, but not in their services, since they all seem to concentrate on consulting.
\end{abstract}

Key words: tourism clusters; support institutions; public institutions; competitiveness. 


\section{Introdução}

A discussão sobre aglomerações territoriais e recursos competitivos teve seus primórdios em Marshall (1925). Quando o autor fez referência à presença de fornecedores, e mesmo a um conhecimento coletivo que pairava no ar, pode-se perceber um nexo com o que se chamou posteriormente de recursos estratégicos. Os trabalhos de autores como Becattini (1979) reforçaram essa percepção e indicaram que havia semelhanças entre seus achados e os de Marshall (1925). Temse, então, que um dos pontos primordiais da existência dessas aglomerações é a presença de recursos que são coletivos em relação às empresas nelas inseridas, mas são privados em relação às empresas de fora. São esses recursos que garantem maior competitividade às empresas aglomeradas. Tais ideias reportam-se à Visão Baseada em Recursos (Resource-Based View), a qual indica que a geração de vantagens competitivas se dá pelo acesso e/ou controle de recursos estratégicos (Barney, 1991). Dentre os recursos estratégicos aos quais a empresa pode ter acesso ou controle em uma aglomeração, estão as instituições (Asheim \& Isaksen, 2002; Paniccia, 1998; Schmitz, 1993).

O papel das instituições foi descrito como essencial dentro de uma aglomeração, tendo em vista sua capacidade de prestar serviços para a indústria de maneira mais focada e a preços mais baixos, em função de sua escala (Brusco, 1993; Schmitz, 1993). Esse suporte se dá pelo desenvolvimento de apoio institucional não financeiro (Brusco, 1993), e as instituições têm, ainda, a habilidade de captar externamente e internalizar na aglomeração informações relevantes para as empresas, através de sua rede de contatos com suas congêneres de fora da aglomeração e mesmo de outros países (Bellandi \& Caloffi, 2008). Igualmente, é papel das instituições o fornecimento de novas informações acerca de tecnologia e oportunidades disponíveis para toda a rede, segundo Molina-Morales, López-Navarro e Guia-Julve (2001). Isso pode diminuir os custos de aquisição de informação que, para as pequenas empresas, podem ser relativamente pesados. Dessa forma, as instituições funcionam como repositórios, nos quais o conhecimento é armazenado e repassado para toda a rede.

Essas instituições podem assumir várias configurações, como associações empresariais, institutos de tecnologia, agências governamentais e fontes financiadoras. De certa forma, esses serviços oportunizam relações de cooperação e competição que se ensejam no contexto da rede interorganizacional aglomerada. Ou seja, a demanda das empresas e o fornecimento por parte das instituições fazem com que se estabeleçam as redes interorganizacionais como modelo de organização mais ajustado a esse tipo de realidade.

O estudo sobre essas redes tem se amplificado no Brasil, conforme atestam trabalhos recentes de Balestrin, Verschoore e Reyes (2010) e Andrighi, Hoffmann e Andrade (2011). Tal crescimento parece estar pautado pela adoção desse modelo de organização por parte das empresas como meio que aprimorar competitividade, pois as redes permitem que as empresas concentrem-se em suas competências essenciais (Freeman, Edwards, \& Schroder, 2006); promovem a inovação e a produtividade (L. C. Rodrigues, Macari, \& Riscarolli, 2007; Mesquita \& Lazarini, 2010); facilitam a aprendizagem, o incremento da escala, o poder de mercado e o acesso a soluções (Verschoore \& Balestrin, 2008); além de diminuir o custo do capital (Magalhães, Daudt, \& Phonlor, 2009).

A atividade turística no Brasil reúne condições de ampla diversidade de atrativos e se apresenta com grande variabilidade de fluxo. Depois da retração registrada em 2009, em 2010 o turismo internacional no Brasil voltou a crescer, com 7.182 mil desembarques e geração de receita cambial de US\$5.317 milhões. A perspectiva é positiva para os próximos anos, considerando tanto a Copa do Mundo de 2014 quanto as Olimpíadas em 2016. Em termos de variabilidade de fluxo, como ilustração, destaca-se que os últimos dados disponíveis sobre a demanda turística no estado do Amazonas, que é tipicamente ligada ao turismo de selva, apontou o ingresso de cerca de 54 mil pessoas, somadas a outras 439 mil que se destinaram à hotelaria urbana no ano de 2008 (Secretaria de Estado de Planejamento e Desenvolvimento Econômico, 2009). No mesmo período, em um destino mais ligado a sol e praia, como Santa Catarina, o ingresso foi de mais de 4.303 mil turistas (Santa Catarina Turismo S/A [Santur], 2006). 
As destinações turísticas são aglomerações de empresas em torno de um atrativo turístico geográfico, histórico e/ou cultural. Nesse caso, a aglomeração é a forma precípua de localização da indústria turística, e a formação de redes é típica nessa atividade, considerando que é um produto baseado na experiência proporcionada pelo atrativo em si e por várias empresas de maneira complementar (Scott, Cooper, \& Baggio, 2008).

Em termos de estudos sobre destinação, Scott, Cooper e Baggio (2008) apontam que os pesquisadores têm tido interesse em três elementos: os atores, os recursos e as relações. Os atores, chamados de nós das redes, executam atividades e se relacionam com outros atores, além de controlar recursos e transferir conhecimento que facilitem esse controle. Eles são heterogêneos em termos de tamanho e função, e tanto podem ser operadores comerciais como organizações de coordenação regional. Os recursos trocados entre os atores podem incluir o conhecimento e os valores monetários. As relações são consideradas as transações entre os atores, que envolvem a transformação desses recursos, complementam Scott et al. (2008). Este estudo se pauta nos atores e indiretamente nos recursos.

A existência de instituições de suporte à atividade turística foi inicialmente detectada por Schmitz (1993), em seu estudo sobre aglomerações de manufatura no trabalho e, posteriormente, por Beritelli (2011). Assim, este trabalho parte do suposto de que a existência de um conjunto maior de atores, em especial de instituições de suporte e seus serviços, traz vantagens competitivas para a empresa presente na destinação turística, e que nessas destinações existem tais instituições e serviços.

Dessa forma, o objetivo central deste trabalho é avaliar as instituições de suporte à atividade turística em destinações turísticas na região do litoral norte de Santa Catarina. Para isso, este artigo está organizado em cinco partes. Nesta primeira, é apresentada a introdução do trabalho; na segunda, discute-se a fundamentação teórica da pesquisa; na terceira, por sua vez, detalha-se a metodologia empregada. Já na quarta, evidenciam-se os resultados e a discussão. Na quinta, por fim, estão as conclusões, limites e recomendações.

\section{Fundamentação Teórica}

O estudo sobre redes pode ser compreendido com ao menos três enfoques distintos. No primeiro, estão as redes sociais, cujo escopo de pesquisa centra-se nas relações entre indivíduos. No segundo, estão as redes de empresas, em que os entes estabelecem entre si relações horizontais e/ou verticais. Finalmente, estão as redes interorganizacionais, nas quais, além de se encontrar empresas, estão inseridos outros atores, como governo e entidades do terceiro setor. Este último é o enfoque deste trabalho, pelo fato de o turismo ser uma atividade aglomerada territorialmente, e por envolver uma rede complexa com um grande número de atores coprodutores de uma variedade de produtos e serviços (Haugland, Grønseth, \& Aarstad 2011; Scott et al., 2008), com base tanto em contratos formais como informais (Beritelli, 2011).

A pesquisa sobre redes em contexto de aglomeração territorial já envolveu distintos objetos, que vão da indústria de calçados (Baldi, Milano, \& Vieira, 2006) até a bioquímica (Whittington, OwenSmith, \& Powell, 2009). Contudo, sobre turismo e especialmente no Brasil, os trabalhos se concentram nos últimos três anos, como se vê nas contribuições de Hocayen-da-Silva e Teixeira (2009), sobre turismo urbano em Curitiba; de Donaire, Silva e Gaspar (2009) sobre turismo setorial; de A. Rodrigues e Rodrigues (2009) e de Czajkowski e Cunha (2010) sobre turismo rural; de Andrighi e Hoffmann (2010) sobre turismo de inverno; e de Sacramento, Teixeira e Cerqueira (2010) também sobre turismo urbano, na cidade de Aracaju (SE).

Internacionalmente, o avanço parece mais significativo, pois a temática é mais abrangente. Scott et al. (2008) estudaram quatro destinos turísticos na Austrália, sob o ponto de vista de configuração de rede, e concluíram que, em destinos mais industrializados, a estrutura interorganizacional é mais 
coesa. Baggio, Scott e Cooper (2010), apesar de reafirmarem a complementaridade do produto/serviço turístico, mostraram que estar em uma destinação turística não é condição suficiente para que haja cooperação. $\mathrm{O}$ trabalho também mostrou que um determinante importante para a difusão do conhecimento em um sistema socioeconômico como um destino turístico é a presença de uma rede estruturada que conecte diferentes stakeholders, além da existência de forte coesão local. Beritelli (2011) estudou um destino turístico nos Alpes Europeus, e apontou que as relações tanto podem se dar de maneira contratual como não contratual; que as variáveis ligadas à troca de informação e comunicação se vincularam mais intensamente nas relações não contratuais; e que a afinidade social influencia fortemente a colaboração baseada no relacionamento. Haugland, Grønseth e Aarstad (2011) trataram de entender o desenvolvimento do destino turístico como um processo multinível. Uma das propostas derivadas da ferramenta de análise empregada por esses últimos autores é que, na medida em que a integração ao nível da destinação se incrementa, substituindo os relacionamentos individuais entre atores, a habilidade do destino em desenvolver estratégias multinível também se incrementa.

A discussão sobre o papel das instituições em aglomerações territoriais remete a duas abordagens distintas e complementares. Por um lado está a própria noção de existência da aglomeração em si, como um fenômeno econômico (Marshall, 1925), mas também social (Brusco, 1982). Por outro, está a compreensão sobre o papel do que se pode chamar de efeito aglomeração (Hoffmann, Bandeira-de-Mello, \& Molina-Morales, 2011), que trata do impacto que o fato de estar presente em uma aglomeração exerce sobre o desempenho das empresas. No Brasil, e também em outros países, esse impacto tem sido medido em termos de recursos estratégicos (Martínez-Fernández, 2001). A existência desses recursos na aglomeração é que interessa para o objetivo deste trabalho. Ao falar-se de recursos estratégicos, reporta-se aos escritos de vários autores, como Barney (1991) e Wernerfelt (1984). Esses autores estabeleceram que as empresas, como conjuntos de recursos tangíveis, intangíveis e humanos, baseiam sua vantagem competitiva na posse e/ou no acesso a recursos competitivos. Isso faz com que elas se esforcem para gerar internamente esses recursos. Os recursos de controle são aqueles de que a empresa pode dispor, enquanto os de acesso podem gerar vantagem, mas a empresa não pode exercer a tomada de decisão direta sobre seu emprego e/ou fim. No caso das aglomerações territoriais, o que se percebe é que vários trabalhos que tratam do tema (Malmberg \& Power, 2005; Paniccia, 1998; Schmitz, 1993; Whittington et al., 2009) indicam a existência de recursos de acesso. Dessa forma, entende-se que a aglomeração territorial pode propiciar o surgimento de redes como modelo organizacional, ao mesmo tempo em que gera recursos de acesso.

Compreendendo a destinação turística como uma aglomeração, percebe-se que esses recursos são capazes de gerar vantagem competitiva para toda a destinação quando podem ser acessados, o que nem sempre acontece. Parrilli e Sacchetti (2008) salientam que, quando uma aglomeração é dominada por uma empresa maior, que funcione como nó central da rede, ela pode não ter interesse em desenvolver seus fornecedores, diminuindo ao mínimo a troca de recurso entre eles.

Os recursos já encontrados em aglomerações de distintas indústrias podem ser de diversos tipos. A confiança tem sido apontada como um recurso existente na aglomeração territorial, mas também em outros tipos de redes, como indicado por Franco (2007) e Zylberstajn e Farina (2010). Essa confiança está baseada na redundância dos laços entre as empresas e serve de estímulo para que estas acumulem informação que pode estar vinculada às demais. Por exemplo, um caso estudado por Zylberstajn e Farina (2010) mostrou que a proximidade entre produtores é importante, pois, de certa forma, condiciona o comportamento de todos com vistas a manter sua reputação e, naquele caso, manter o preço prêmio de seus produtos. No turismo, Nunkoo e Ramkissoon (2012) encontraram relações positivas entre a confiança dos residentes nas instituições de suporte e os benefícios derivados da existência dessas instituições.

Outro recurso presente na aglomeração é a mão de obra qualificada. Talvez por uma questão de custo de oportunidade, um trabalhador, ao deixar uma empresa de uma indústria aglomerada territorialmente, tenderá a buscar emprego em outra empresa da mesma indústria. Essa mobilidade interna da mão de obra propicia a preservação do conhecimento tácito acumulado pelo trabalhador dentro dos limites da própria aglomeração industrial. Mesmo que isso signifique uma perda isolada 
para a empresa que está sendo deixada, há um ganho coletivo em comparação ao deslocamento extraindustrial (Molina-Morales, López-Navarro, \& Guia-Julve, 2001).

Um terceiro recurso, que tem sido muito discutido, é a cooperação, que pode se dar de distintas formas. A rede aglomerada é uma comunidade de pessoas e empresas que têm um convívio constante pela aproximação, retratada na vida extraprofissional existente. Assim, as pessoas acabam encontrando-se nos distintos eventos sociais, e esses laços anteriores podem facilitar a constituição da própria rede, conforme Baldi, Milano e Vieira (2006) e Parrilli e Sacchetti (2008). Isso cria uma interdependência que sobrepassa aquelas relações puramente econômicas ou de negócios (MolinaMorales et al., 2001), e acaba redundando na formação de redes, conforme Parrilli e Sacchetti (2008). Como um dos resultados dessa cooperação, está o incremento da capacidade de inovar e de introduzir ou melhorar produtos, serviços e processos (Doloreux \& Mattson, 2008).

O papel das instituições tem se revelado um quarto recurso presente nas aglomerações. Sobre as instituições, pode-se notar que há diferentes aspectos a discutir. Em um trabalho sobre a indústria cerâmica, foi detectado que uma mesma indústria, em localizações diferentes, pode ter instituições distintas localmente (Hoffmann, 2002). Alguns autores destacam a existência de diferentes instituições de suporte (Paniccia, 1998; Schmitz, 1993), como: associações empresariais; instituições de tecnologia; agências governamentais, locais, regionais e ou nacionais; e mesmo fontes públicas e privadas de financiamento. Ou seja, pode-se partir do pressuposto de que nas destinações existem instituições, mas não necessariamente que elas sejam as mesmas em todos os tipos de aglomerações.

Os serviços que podem ser desenvolvidos pelas instituições são igualmente diversificados. Elas diminuem os custos das empresas através da oferta de serviços públicos (Dei Ottati, 1987), chamados por Benton (1993) de serviços reais; melhoram a comunicação externa das empresas (Swan \& Newell, 1995); regulam os impactos sobre o meio ambiente ecológico (Paniccia, 1998); corroboram o surgimento de novas empresas (Malmberg \& Power, 2005); podem dar suporte ao desenvolvimento interno de soluções tecnológicas necessárias e assim reduzir seus custos de aquisição (Freeman et al., 2006); auxiliam na internacionalização de empresas (Bellandi \& Caloffi, 2008); e são coadjuvantes na transferência de conhecimento (Hoffmann et al., 2011). A partir de tantas atribuições, pode-se intuir que as instituições de suporte às indústrias inseridas em uma aglomeração territorial, que se governe como uma rede interorganizacional, formam um importante atrativo para as empresas, além de aprimorarem a competitividade interna da própria aglomeração sempre que forem capazes de gerar serviços reais. De certa forma, esses serviços reais oportunizam relações de cooperação e competição que se ensejam no contexto da rede interorganizacional aglomerada.

Quanto ao financiamento das instituições no Brasil, este tem se mostrado distinto ao que ocorre no exterior. Brusco (1993), ao escrever sobre a prestação dos serviços reais, concentrou sua pesquisa nas instituições subvencionadas pelo poder público. No entanto, a realidade no Brasil pode se distanciar daquela verificada pelo autor, considerando que a sociedade civil tem se organizado para responder às demandas sociais não atendidas pelo governo, em seus distintos níveis. Da mesma forma, autores como Esser, Hillebrand, Messner e Meyer-Stamer (1994) destacam a importância das associações da sociedade civil que são capazes de gerar competitividade para as empresas. No trabalho apresentado por Martínez-Fernández (2001), evidencia-se que a associação local da indústria cerâmica em Castellón (Espanha) é financiada com recursos das empresas e seu prestígio é alto no setor, o que faz com que sempre haja disputa política por seu controle. Isso parece indicar que pode haver maior senso de pertinência quando o financiamento ocorre dessa forma.

As instituições também podem servir como elo entre as empresas da aglomeração e outros atores de fora da aglomeração (Bellandi \& Caloffi, 2008), e podem se tornar um ambiente no qual se estabelecem as redes sociais entre os entes aglomerados (Baldi et al., 2006; Martínez-Fernández, 2001). Foi indicado por Dwyer e Kim (2003) que o gerenciamento da destinação turística é um recurso capaz de ampliar a competitividade da destinação. Aqueles autores esclarecem que a interação entre os agentes públicos e do terceiro setor podem definir temas importantes, como a promoção da destinação, por exemplo. Dessa forma, além das relações diádicas instituição-empresa, podem ocorrer outras que 
envolvam conexões instituições-instituições, o que se supõe poder diminuir a sobre ou suboferta de serviços, ou mesmo a sua complementaridade.

Como já salientado, Esser et al. (1994) mostraram que a existência das instituições e seus serviços relaciona-se à competitividade de uma aglomeração de empresas. As instituições, através de suas atividades, como mínimo, diminuem alguns custos relacionados aos serviços próprios para o setor (Brusco, 1993). Talvez por isso, elas auxiliam o surgimento de novas empresas (Malmberg \& Power, 2005). Além disso, a existência de instituições como universidades e laboratórios de pesquisa mostrouse positivamente relacionada à quantidade de pesquisa e desenvolvimento entre empresas presentes em aglomeração territorial pesquisada por Doloreux e Mattson (2008).

Desde um ponto de vista sistêmico, Esser et al. (1994), de maneira geral, e, posteriormente, Dwyer e Kim (2003), especificamente falando de turismo, evidenciaram que a competitividade não deriva de apenas um âmbito (micro ou macro), mas é um processo multinível. No modelo de Dwyer e Kim (2003), a administração da destinação - em que se encontram as instituições de suporte - as condições situacionais e de demanda vão impactar em indicadores de desempenho da destinação, como fluxo e gastos dos turistas, por exemplo.

Em relação aos tipos de instituições, Schmitz (1993) enumera dois: as públicas e as intermediárias. Conforme o autor, as instituições públicas, como universidades e escolas de ensino tecnológico, têm papel importante, pois tratam de formar mão de obra e promover a pesquisa. As intermediárias são aquelas que contribuem na elaboração de normas para a produção e a comercialização dos produtos e serviços, fornecem assessorias em questões trabalhistas, como as associações comerciais, industriais e de empresários, e os sindicatos patronais. Além disso, elas podem exercer representação política e apoio para projetos de inovação tecnológica. Nesse último grupo, ainda se encontram os bancos, que podem prover créditos específicos para o setor e mesmo incentivos ao comércio internacional.

Salienta-se também que a constituição dessas instituições deve ter um apelo objetivo quanto à construção de vantagem competitiva para a rede. Castro, Bulgacov e Hoffmann (2011), ao estudarem uma rede no estado do Paraná, concluíram que, quando a instituição que exerce a governança da rede não gera os resultados em termos de competitividade, ela cria dificuldades à cooperação. Como escreve Kwasnicka (2006), a formalização pode ter um papel importante no gerenciamento da rede, mas, ao que se nota pelos resultados de Castro et al. (2011), essa não é uma condição suficiente para a sua manutenção. Mesmos em redes formais, a assimetria de interesses pode causar impacto negativo nas vantagens que tal ambiente pode proporcionar, como evidenciaram Soares, Castro, Brito e Alves (2011). A respeito do turismo, o estudo de Beritelli (2011) mostrou que as relações entre empresa e instituições são tipicamente formais, enquanto que entre empresas elas podem ser também informais.

A discussão sobre turismo e instituições da maneira mais específica é recente. Trimarchi (2004) já definiu a existência de distrito cultural industrial, que não se distancia da definição clássica de Marshall (1925), pois "a única peculiaridade relevante é a natureza dos bens produzidos" (p. 117). No caso estudado por esse autor, evidencia-se o trabalho do governo local e de suas instituições a fim de estabelecer a cidade de Siena, na Itália, como um destino turístico cultural. André (2004), ao discutir o turismo cultural, também salientou que o êxito da gestão de uma destinação turística pressupõe maior diálogo entre os agentes, a fim de que se trate o destino de forma integral. Afirma: "incorporando todos os recursos e/ou produtos existentes a uma oferta global, articulada no território e de acordo com o tecido social e econômico presente no mesmo" (p. 160). André (2004) relatou também que o uso do planejamento estratégico para dinamizar o turismo da cidade de Figures (Espanha) se deu com a participação do poder público, de agentes empresariais e do terceiro setor. Ainda na Espanha, Bonet (2004) descreveu o crescimento do turismo na cidade de Barcelona, que foi dinamizado a partir da constituição de um consórcio público-privado que uniu a Prefeitura, a Câmara de Comércio, Indústria e Navegação e a Fundação de Promoção de Barcelona. Como fruto dessa organização, a partir das Olimpíadas de 1992, Barcelona passou de uma urbe industrial desconhecida para um dos destinos culturais europeus mais demandados, com incremento no número de pernoites de 7,83\% a.a., no período 1990-2002. A instituição criada possui cinco diretorias: administração e organização; 
marketing; imprensa e comunicação; informática e novas tecnologias; e comercial e novos projetos, o que mostra que esse tipo de instituição tanto tem impacto no desempenho da destinação, como pode ofertar diversos serviços para esse fim.

\section{Metodologia da Pesquisa}

Esta pesquisa caracteriza-se como um estudo de caso, de caráter descritivo, com abordagens qualitativa e quantitativa. O método de estudo de caso múltiplos é bastante comum na pesquisa em turismo, como se pode notar nos estudos de Pavlovich (2003), Scott et al. (2008), Shih (2003) e Wong, Mistillis e Dwyer (2011). Foram pesquisados os municípios da chamada Costa Verde e Mar que integram a Associação dos Municípios da Região da Foz do Rio Itajaí (AMFRI), do litoral norte de Santa Catarina: Balneário Camboriú, Bombinhas, Itajaí, Itapema; Navegantes, Penha; Porto Belo, excluindo-se da lista Camboriú, Ilhota e Luiz Alves por não serem banhadas pelo mar e pelo fato de o turismo nessas últimas cidades não ser o de sol e praia. A cidade de Balneário Piçarras também foi excluída da pesquisa pelo fato de o acesso não ter sido possível no momento da aplicação do questionário. A escolha por essa região se deveu ao fato de ser a que mais atraiu turistas no período estudado (Santur, 2008).

Foi realizado um censo com todas as instituições públicas, privadas e do terceiro setor que possuíam algum tipo de ligação com o desenvolvimento de atividades de suporte ao turismo nas cidades citadas. Para determinar-se a listagem das instituições, foram consultadas as prefeituras de cada município. A fim de completar a informação, as instituições pesquisadas também deram orientações que confirmaram e/ou ampliaram a listagem fornecida por cada prefeitura.

Os dados utilizados nesta pesquisa se originam de fontes primárias e secundárias. Os dados primários foram obtidos por intermédio da aplicação de um questionário com perguntas abertas e fechadas, conforme a classificação de Richardson (1985), que possibilitaram a elaboração de um trabalho de análise com características qualitativas e quantitativas. As perguntas fechadas foram respondidas dentro da escala contínua intervalar de 1 a 5 , sendo 1 para a menor intensidade e 5 para a maior intensidade. O detalhamento dos objetivos e os indicadores utilizados são apontados no Quadro 1. Os respondentes foram os dirigentes das instituições, através de um procedimento de agenda prévia. A aplicação foi feita de maneira pessoal, a fim de manter o controle sobre o fornecimento dos dados.

Outra etapa quantitativa envolveu os dados secundários sobre desempenho do turismo em cada cidade, que foram coletados por meio de pesquisa documental efetuada em meio eletrônico disponibilizado pela Santa Catarina Turismo S/A (Santur), através do sítio eletrônico www.santur.sc.gov.br. A intenção inicial era utilizar dados de 2009, os mais atualizados. Mas essa ideia foi abandonada, pois estavam disponíveis apenas as informações de Balneário Camboriú, Itajaí e Porto Belo. Então, utilizaram-se os dados de 2004 e 2008. Como não havia dados do período em análise (2004-2008) para a cidade de Navegantes, ela foi excluída desta etapa. Já para a cidade de Penha, o cálculo foi realizado entre 2005 e 2008, pois eram os únicos anos disponíveis na referida fonte quando foi realizada a pesquisa do dado $\left(2^{\circ}\right.$ semestre de 2010). E para a cidade de Itapema, o intervalo foi de 2004 e 2007, pois não havia dados da cidade para o ano de 2008.

Com esses elementos, calculou-se a variação entre o primeiro e o último ano disponíveis. Essa escolha se deveu pelo fato de os números entre as cidades serem muito distintos. Por exemplo, mais de 95\% da demanda total de turismo em 2008 entre as cidades estudadas foi para Balneário Camboriú (Santur, 2008). Por se tratar de análise de variação, não se leva em conta o peso que cada cidade tem no turismo da região. Ou seja, em termos absolutos, a variação negativa de $10,16 \%$ em Balneário Camboriú representa mais que o dobro da variação positiva em Porto Belo, da ordem 82,7\% (Tabela 4). O uso da variação permite perceber cada cidade por ela própria, sem o viés eventual que poderia haver entre grandes e pequenos destinos, e elimina-se, assim, a necessidade da variável de controle tamanho. 
O tratamento de dados primários qualitativos contrastou-se às seguintes categorias: existência de instituições; fonte de financiamento; serviços prestados. Quanto aos dados secundários, a estatística descritiva foi aplicada para os estudos preliminares, no caso dos objetivos 1e 2 (apresentados na Tabela 1). O estudo seguinte - objetivo específico 3 - aplicou a análise de correlação de Pearson, para verificar as relações entre a quantidade de instituições e de serviços com a variação nos dados da demanda turística.

Tabela 1

Descrição de Variáveis e Indicadores

\begin{tabular}{ll}
\hline Objetivo & Perguntas do Questionário \\
\hline Determinar a existência de instituições de & Nome da instituição; \\
suporte e sua fonte de financiamento. & Ano de fundação; \\
& Objetivos organizacionais; \\
& Origem de recursos para sua manutenção; \\
& Número de associados contribuintes e não contribuintes; \\
\hline Determinar os serviços prestados pelas & Especificação dos serviços oferecidos; \\
instituições. & Tipo; \\
& Enfase atribuída. \\
\hline & Dados Secundários* \\
\hline Determinar a relação entre as instituições, seus & Demanda turística nacional; \\
serviços e o desempenho competitivo de & Demanda turística internacional; \\
destinações turísticas de Santa Catarina. & Gastos diários por turista nacional; \\
& Gastos diários por turista internacional; \\
& Permanência por turista nacional; \\
& Permanência por turista internacional; \\
& Uso da hotelaria. \\
\hline
\end{tabular}

Nota. Fonte: elaboração própria baseado em Santa Catarina Turismo S/A. $\left(2010^{\mathrm{a}}\right)$. Demanda turística. Sinopse comparativa 2004, 2005 e 2006. Recuperado de Secretaria de Estado de Turismo, Cultura e Esporte; SANTUR - Santa Catarina Turismo S/A; Diretoria de Planejamento e Desenvolvimento Turístico (2006). Pesquisa mercadológica estudo da demanda turística Estado de Santa Catarina - Sinopse comparativa 2004, 2005 e 2006. Recuperado de http://www.santur.sc.gov.br/images/stories/estatisticas/Demanda2006/si_2006_santa_catarina.pdf; Secretaria de Estado de Turismo, Cultura e Esporte; SANTUR - Santa Catarina Turismo S/A; Diretoria de Planejamento e Desenvolvimento Turístico (2008). Pesquisa mercadológica estudo da demanda turística - Estado de Santa Catarina - Sinopse comparativa 2006, $2007 \quad 2008 \quad$ janeiro/fevereiro. $\quad$ Recuperado http://www.santur.sc.gov.br/images/stories/estatisticas/Demanda2008/estado\%202008-1.pdf

\section{Resultados}

Neste item, apresentam-se os resultados do trabalho e uma discussão sobre os mesmos. O ordenamento que se aplicou é o mesmo dos objetivos específicos do trabalho.

\section{Existência de instituições de suporte à atividade turística e financiamento}

Os resultados deste objetivo apontaram quarenta e nove instituições de suporte à atividade turística na região estudada, conforme apresentado na Tabela 2. Essa Tabela mostra também que entre as quarenta e nove instituições pesquisadas, apenas três foram criadas durante o período de análise, sendo duas delas em Itajaí (AMFRI em 2006; SETUR em 2009) e uma em Penha (Sindicato dos hotéis, em 2009). No caso específico da AMFRI, apesar de estar em Itajaí e fomentar o turismo local, 
trata-se de um órgão supramunicipal e, dessa maneira, sua participação pode ter relação com o turismo de toda a região.

A Tabela 2 indica, ainda, que, na região estudada, há vinte tipos distintos de instituições. Na primeira coluna, estão numeradas as instituições, com destaque para aquelas que possuem a palavra turismo, ou suas derivadas, no seu objetivo. Com isso, percebe-se que, entre as vinte listadas, onze estão relacionadas diretamente ao turismo e outras nove têm relação indireta. Percebe-se, igualmente, que todos os municípios possuem secretaria de turismo (SETUR), o que parece indicar a importância que a atividade tem para cada cidade. Nota-se que, em alguns casos, essa secretaria se junta às outras atividades econômicas citadinas, como indústria e comércio, e agricultura.

Além da SETUR, as organizações mais presentes são a associação comercial e industrial, e a câmara de dirigentes lojistas (CDL). Essas duas associações têm escopo específico, sendo a primeira mais voltada à representação política e a CDL mais voltada ao crédito. Maiores detalhes sobre os serviços serão apresentados adiante. Percebe-se, também, que, das vinte organizações ligadas diretamente ao turismo, sete foram criadas a partir de 2001, o que parece indicar que a estrutura é recente.

Em uma análise por cidade, percebe-se que Itajaí e Balneário Camboriú possuem maior número de instituições, com treze cada uma, correspondendo a 53\% do total delas, o que parece compreensível, pois Itajaí e Balneário Camboriú possuem a maior população entre as cidades estudadas. Contudo, as duas com maior demanda turística são Balneário Camboriú e Itapema. No entanto, apesar do mesmo número, elas são distintas em termos de estrutura para o turismo. Em Itajaí, a Secretaria Regional e a AMFRI não são órgãos do município e não atendem demandas apenas da própria cidade, e sim de todas as cidades do entorno. Dessa forma, o crédito de existência dessas instituições deve ser computado, ao menos em parte, para as demais. Das treze instituições itajaienses listadas, três são exclusivas da cidade e com o foco direto em turismo.

Por outro lado, a cidade de Balneário Camboriú, que atrai um dos maiores fluxos turísticos para o estado, é a cidade com a maior quantidade de instituições ligadas ao turismo. Entre as treze listadas, sete têm em seu escopo a palavra turismo. Sua secretaria de turismo é a mais antiga entre as pesquisadas, datada de 1970, quase vinte anos antes da segunda mais antiga (Penha em 1989). Sua estrutura está composta por quatro órgãos com características públicas e privadas.

Como se observa, nas cidades se encontram tanto instituições do tipo pública como intermediária. Chama a atenção o destaque que Schmitz (1993) deu para as públicas, ao incluir entre elas as universidade e escolas de ensino tecnológico, como formadoras de mão de obra. Nessa pesquisa, percebeu-se o papel que o SENAC de Itajaí tem como formador de mão de obra. Embora não tenha sido citada pela prefeitura e também pelas outras instituições, a Universidade do Vale do Itajaí (Univali), campus de Balneário Camboriú, possui um dos bacharelados em turismo mais antigos do Brasil, e a formação de seus estudantes tem sido reconhecida por diversos prêmios. Essa instituição ficou de fora por não ter sido apontada nas listas das prefeituras ou não ter sido citada pelas demais instituições.

Os resultados da presente pesquisa, relacionados às fontes de financiamento das instituições de suporte às atividades turísticas, estão apresentadas também na Tabela 2. Observa-se que, na maioria das instituições pesquisadas, os recursos vêm do Estado ou da prefeitura (dotação orçamentária). Das vinte instituições, nove são financiadas por recursos privados, sendo que, em dois casos, isso é feito de maneira compulsória. Quando não é este o procedimento, percebe-se que muitas destas instituições se mantêm através de mensalidade dos associados, sejam eles pessoas físicas ou jurídicas. De certa forma, isso evidencia que o poder público é o fomentador da atividade na região.

A literatura sobre o tipo de instituição é ainda incipiente. O que se sabe é que nos estudos de Haugland et al. (2011); e Scott et al. (2008) assume-se que um destino turístico é formado por diferentes atores, que se relacionam tanto de maneira forma como informal (Beritelli, 2011). Beritelli (2011) também apontou que as relações entre instituições e empresas se davam de modo formal, em 
seu estudo. Neste estudo, o que se percebeu é que as empresas se associam de maneira formal, o que pode repercutir negativamente em termos de troca de informação, segundo os resultados do estudo de Beritelli (2011).

No texto de Bonet (2004), percebe-se que a prefeitura e o terceiro setor trabalham na administração da destinação, tal como foi recomendado por Dwyer e Kim (2003). A presença desse tipo de instituição foi verificada em todas as cidades, o que pode ensejar, ao menos, potencial para se compor esse trabalho conjunto e a geração de competitividade, tal como ressaltaram Dwyer e Kim (2003) e haviam encontrado Andrighi e Hoffmann (2010) em seu trabalho sobre outra localidade catarinense. Contudo, parece relevante o fato de as instituições ligadas ao turismo terem sido criadas nos últimos dez anos. No caso específico das SETUR, há outro componente de troca de comando (ou há possibilidade, ao menos) a cada quatro anos, o que não permitiria a existência de projetos de longo prazo. Note-se que algumas instituições, principalmente as universidades e centros tecnológicos apontados por Schmitz (1993) e também por Whittington, Owen-Smith e Powell (2009), podem ter grandes vantagens com o tempo, e a elevação de sua curva de aprendizagem através da pesquisa. Então, parece que são as secretarias de turismo que se prestam ao papel de nó da rede de relacionamento, pois se constituem no maior investidor na atividade da região. Ao falarem de nó central da rede, Parrilli e Sacchetti (2008) destacaram como negativa sua existência, mas eles se referiram à empresa e não a um órgão público. Ou seja, essa organização pode ser um nó central e ainda atuar de maneira construtiva para toda a rede, o que, nesse caso, traduz-se em geração de competitividade.

\section{Serviços prestados pelas instituições de suporte}

De acordo com os dados apresentados na Tabela 3, diversos são os objetivos ou funções das quarenta e nove instituições identificadas e pesquisadas. Com intuito de facilitar a análise dos dados, foram pré-selecionados quinze tipos distintos de serviços:

1. Aperfeiçoamento (Ap)

2. Infraestrutura para Eventos (IE)

3. Assessoria de Imprensa (AI)

4. Infraestrutura para Treinamentos (IT)

5. Assessoria Jurídica (AJ)

6. Investimentos (In)

7. Assessoria Técnica (AT)

8. Representação Política (RP)

9. Assessoria Tecnológica (AN)

10.Serviço de Informação (SI)

11.Atividades Comerciais (AC)

12.Treinamento $(\mathrm{Tr})$

13.Atividades Sociais (AS)

14.Ações de Sustentabilidade Ambiental (ASA)

15.Convênios (C) 
A Tabela 3 se propõe a detalhar a prestação de serviços por parte daquelas instituições ligadas ao turismo nas distintas cidades. Para facilitar a análise, tratou-se de sinalizar a intensidade de cada serviço prestado com uma escala de cor, sendo o tom mais fraco para o 1 (intensidade baixa na escala) e o mais forte para o 5 (intensidade alta na escala). As instituições também foram agrupadas por tipo, para se proceder a comparação entre elas nas distintas cidades.

A cidade de Itajaí e Itapema foram as que registraram o maior número de atividades com valores tendendo à parte superior da escala de importância (4 e 5), com vinte e três cada. Em Itajaí, isso pode ser explicado pela presença de duas instituições que são regionais e que entraram na pesquisa (AMFRI e Secretaria Regional); já em Itapema, não há uma razão objetiva para isso. Percebem-se, em Balneário Camboriú, apesar de ser a localidade com maior número de instituições com escopo no turismo, dezesseis serviços que foram considerados como importantes.

Ressalta-se que as atividades da COMTUR e FUMTUR foram direcionadas para a SETUR, pelo próprio entrevistado, o que fez com elas aparecessem sem nenhum valor nessa Tabela 2. Entre as SETUR, os serviços destacados foram o aperfeiçoamento, as assessorias e a representação política. Merece esclarecimento a SETUR de Itapema, onde quase todos os serviços da escala foram apontados com nota 5, o que influenciou o resultado anteriormente assinalado. Atividades comerciais, sociais, convênios, treinamento e ações de sustentabilidade ambiental foram pouco priorizadas. Entre as outras organizações, novamente as assessorias foram as mais prevalentes, com valores 4 e 5, com exceção do tipo tecnológica e convênios.

De modo geral, as instituições as quais assumem a maioria das ações com ênfase nos destinos turísticos são as públicas mais próximas do que foi indicado por Benton (1993), ao contrário do que foi visto no estudo de Martínez-Fernández (2001), em que se sobressaíram as instituições intermediárias. Os serviços prestados pelas instituições podem ser a forma como a destinação cria seus recursos competitivos, como já indicado na literatura (Dwyer \& Kim, 2003). E esses recursos, que são do tipo acesso, conforme Barney (1991), auxiliariam na construção da competitividade das empresas e, no caso do turismo, da própria destinação, como afirmaram Dwyer e Kim (2003). De certa forma, esse resultado também dista daquele ressaltado por Bonet (2004), quando estudou Barcelona. Naquele caso, Bonet (2004) indicou que a gestão da destinação é feita de maneira consorciada e envolve tanto empresas como governo local, de acordo com o recomendado por Dwyer e Kim (2003) ao discutirem o tema. 
Tabela 2

\section{Listagem das Instituições de Suporte Pesquisadas}

\begin{tabular}{|c|c|c|c|c|c|c|c|c|c|c|c|}
\hline & Tipo de Instituição e total por cidade & Financiamento & Filiação & Associadas & $\begin{array}{l}\text { Bal.Cam- } \\
\text { boriú - } 13\end{array}$ & $\begin{array}{c}\text { Itajaí } \\
13\end{array}$ & $\begin{array}{l}\text { Navegantes } \\
\mathbf{5}\end{array}$ & $\begin{array}{l}\text { Porto Belo } \\
5\end{array}$ & $\begin{array}{c}\text { Bombinhas } \\
5\end{array}$ & $\begin{array}{c}\text { Itapema } \\
4\end{array}$ & $\begin{array}{c}\text { Penha } \\
4\end{array}$ \\
\hline 1. & SEBRAE & & & & & 1973 & & & & & \\
\hline 2. & $\begin{array}{l}\text { Comtur - Comissão Municipal de } \\
\text { Turismo }\end{array}$ & Pública & $\begin{array}{l}\text { Indepen- } \\
\text { dente }\end{array}$ & - & S.D. & 1996 & & & & & \\
\hline 3. & CDL - Câmara de Dir. Lojistas & & & & 1977 & 1942 & 2003 & 1995 & 1992 & 1991 & 2003 \\
\hline 4. & $\begin{array}{l}\text { Fund. de Preservação da Memória } \\
\text { Histórica }\end{array}$ & & & & & 1925 & & & & & \\
\hline 5. & $\begin{array}{l}\text { Secretaria Regional - Gerência de Cultura } \\
\text { e Esporte, Turismo }\end{array}$ & Pública & $\begin{array}{l}\text { Governo } \\
\text { Estado }\end{array}$ & 9 & & 2003 & & & & & \\
\hline 6. & $\begin{array}{l}\text { AMFRI - Consórcio Intermunicipal de } \\
\text { Turismo Costa Verde e Mar }\end{array}$ & Pública & - & 11 & & 2006 & & & & & \\
\hline 7. & Fundação Cultural* & & & & 1994 & 2000 & 2000 & S.D. & & & \\
\hline 8. & $\begin{array}{l}\text { Secretaria ou Fundação Municipal de } \\
\text { Meio Ambiente }\end{array}$ & & & & 1989 & 2000 & 2001 & 2001 & & & \\
\hline 9. & SESC - Serviço Social do Comércio & & & & & 1946 & & & & & \\
\hline 10. & SINE & & & & 1975 & 1975 & & & & & \\
\hline 11. & SENAC - Serviço Nacional do Comércio & $\begin{array}{l}\text { Privada- } \\
\text { compulsório }\end{array}$ & Fecomércio & $\begin{array}{l}\text { Todas } \\
\text { comércio }\end{array}$ & & 1949 & & & & & \\
\hline 12. & ACI - Associação Coml. e Indl. & & & & 2004 & 1929 & 1990 & S.D. & $\begin{array}{c}1999 / \\
2004 * *\end{array}$ & 2001 & 1993 \\
\hline 13. & SETUR - Secretaria de Turismo & Pública & Prefeitura & - & 1970 & 2009 & 1999 & 1993 & 1997 & 1998 & 1989 \\
\hline 14. & FUMTUR - Fund. Mun. de Turismo & $\begin{array}{c}\text { Privada- } \\
\text { Compulsório }\end{array}$ & SETUR & - & 1994 & & & & & & \\
\hline 15. & Aguitur & Privada & - & 78 & 2001 & & & & & & \\
\hline
\end{tabular}

Continua 


\section{Tabela 2 (continuação)}

\begin{tabular}{|c|c|c|c|c|c|c|c|c|c|c|c|}
\hline & Tipo de Instituição e total por cidade & Financiamento & Filiação & Associadas & $\begin{array}{l}\text { Bal.Cam- } \\
\text { boriú - } 13\end{array}$ & $\begin{array}{c}\text { Itajaí } \\
13\end{array}$ & $\begin{array}{c}\text { Navegantes } \\
5\end{array}$ & $\begin{array}{l}\text { Porto Belo } \\
5\end{array}$ & $\begin{array}{c}\text { Bombinhas } \\
5\end{array}$ & $\begin{array}{c}\text { Itapema } \\
4\end{array}$ & $\begin{array}{c}\text { Penha } \\
4\end{array}$ \\
\hline 16. & $\begin{array}{l}\text { ABBTUR - Associação Bras. de } \\
\text { Bacharéis em Turismo }\end{array}$ & Privada & - & 63 & 1991 & & & & & & \\
\hline 17. & $\begin{array}{l}\text { Associação das Pousadas e Hospedarias } \\
\text { Alternativas }\end{array}$ & Privada & - & 60 & 2000 & & & & & & \\
\hline 18. & Convention and Visitors Bureau - CVB & Privada & $\begin{array}{l}\text { CVB } \\
\text { Estadual }\end{array}$ & 112 & 2002 & & & & & & \\
\hline 19. & $\begin{array}{l}\text { AMPE - Associação das Pequenas } \\
\text { Empresas }\end{array}$ & & & & 1996 & & & & & & \\
\hline 20. & $\begin{array}{l}\text { Sindicato dos Empregadores em Hotéis, } \\
\text { Bares, Rest. e Similares }\end{array}$ & Privada & - & Diversos & & & & & $2002 * * *$ & 1992 & 2009 \\
\hline
\end{tabular}

Nota. S.D. não informado. $\mathrm{O}$ ano em negrito indica a primeira instituição criada em cada cidade.

* Também ligadas à preservação da memória histórica; ** Há duas entidades empresariais com escopo semelhante; *** Parece funcionar mais como uma associação para desenvolvimento do turismo que um sindicato. 
Tabela 3

Síntese da Relação entre Instituições com Escopo em Turismo e Serviços Prestados - Todas as Cidades

\begin{tabular}{|c|c|c|c|c|c|c|c|c|c|c|c|c|c|c|c|}
\hline Nome da Instituição & Ap & AI & AJ & AT & $\mathbf{A N}$ & $\mathbf{A C}$ & AS & $\mathrm{C}$ & IE & IT & In & $\mathbf{R P}$ & SI & $\operatorname{Tr}$ & ASA \\
\hline SETUR - Itajaí (ITJ) & 5 & 3 & 3 & 5 & & & 3 & 3 & 3 & 3 & 5 & 3 & & 3 & \\
\hline SETUR - Navegantes & & 3 & 3 & 4 & & & & 4 & 2 & 2 & & 5 & 3 & & \\
\hline SETUR - Balneário Camboriú (BC) & 5 & 3 & 3 & & & & 3 & 2 & 3 & 3 & & 5 & 3 & & \\
\hline SETUR - Itapema (ITP) & 5 & 5 & 5 & 5 & 5 & & 5 & 5 & 5 & 5 & 5 & 5 & 5 & 5 & 5 \\
\hline SETUR - Penha & 4 & 4 & 4 & 4 & 4 & & & & & & 3 & & 5 & & \\
\hline SETUR - Bombinhas (BBS) & 3 & 4 & 4 & 4 & 3 & & & & & & & 4 & 4 & 3 & \\
\hline SETUR - Porto Belo & 5 & 5 & 5 & 5 & 4 & & & & & & & 5 & & & \\
\hline COMTUR - ITJ & & & 3 & 3 & & & & & & & & & & & \\
\hline \multicolumn{16}{|l|}{ COMTUR - BC } \\
\hline \multicolumn{16}{|l|}{ FUMTUR - BC } \\
\hline Secretaria de Desenvolvimento Regional - ITJ & 5 & 5 & 5 & 3 & 3 & & 3 & & 3 & 3 & 3 & 3 & 3 & 3 & \\
\hline AMFRI - ITJ & 4 & & 3 & 5 & 3 & & 2 & 4 & 5 & 5 & 5 & 5 & 5 & & 2 \\
\hline SENAC - ITJ & 5 & 3 & 3 & 4 & & 4 & 3 & 4 & 5 & 5 & 5 & 3 & 3 & 5 & 4 \\
\hline Aguitur - BC & 5 & 5 & & 3 & & 5 & 3 & 5 & & & & 4 & 3 & & \\
\hline ABBTUR- BC & 3 & & 3 & & & & & 4 & 4 & 4 & & 5 & 3 & & \\
\hline Associação das Pousadas e Hospedarias BC & & & & & & & 2 & & & 3 & 3 & 3 & 3 & & \\
\hline Associação de Pousadas e Hotéis - BBS & 4 & 4 & 2 & 4 & 2 & 3 & 3 & 3 & 3 & 2 & 2 & 3 & 3 & 4 & 4 \\
\hline Convention e Visitors Bureau- BC & 3 & 3 & 2 & & & 3 & 3 & & 3 & 3 & & 3 & 3 & 3 & \\
\hline Sindicato dos Hotéis, Restaurantes - ITP & 5 & 1 & 5 & 5 & 1 & 1 & 5 & 5 & 1 & 2 & 4 & 5 & 5 & 5 & 5 \\
\hline
\end{tabular}


Como foi visto nos resultados do objetivo anterior e novamente aqui, esses atores estão presentes, mas quem assume maior empenho são as instituições públicas. Ou seja, esses são os serviços reais apontados por Benton (1993).

$\mathrm{Na}$ discussão sobre serviços chamam a atenção os tipos que foram encontrados. As assessorias, que foram prevalentes, assumem um caráter de menor investimento em capital. Já aqueles serviços que poderiam melhorar a comunicação entre as empresas, conforme Swan e Newell (1995), como a existência de infraestrutura de treinamentos, serviços de informação e treinamento, receberam pouca ênfase. Mesmo a regulação do impacto sobre o meio ambiente, apontada por Paniccia (1998), pode ocorrer de forma precária, considerando que quase não se ressaltou o item ações de sustentabilidade ambiental.

Baggio et al. (2010), ao falarem de complementaridade do produto/serviço turístico, reportaram-se mais à relação fornecedor-empresa. No entanto, pode-se pensar que, em termos de turismo, essa complementaridade dever-se-ia estender também entre as instituições de suporte à atividade, em termos do tipo de serviços que prestam. Visualmente, fica claro, a partir da Tabela 3 , que muitos serviços geram poucas preocupações para as instituições. No trabalho de Nunkoo e Ramkissoon (2012), a confiança nas instituições por parte dos residentes (entendam-se empresas também) é derivada dos benefícios que elas geram. Como essa complementaridade parece não ser plena, entende-se que seus serviços e os benefícios gerados por eles também não o são, o que pode ter um impacto negativo na percepção sobre a utilidade dessas organizações.

\section{Relação entre instituições, serviços e desempenho}

A Tabela 4 mostra que quase todas as cidades tiveram perdas no seu fluxo de turistas, sejam eles nacionais, internacionais ou ambos, como foi o caso de Balneário Camboriú. Porém, essa perda de fluxo não se refletiu em termos de receitas geradas, que cresceram em todas as cidades, com exceção de Penha e Porto Belo, no caso de turistas internacionais. Essa compensação certamente adveio do incremento significativo dos gastos dos turistas em todas as destinações. A taxa de ocupação variou negativamente em duas cidades - Bombinhas e Penha - e, registra-se, o número de pernoites em hotelaria diminuiu em todas as cidades, menos em Bombinhas. 
Tabela 4

\section{Dados de Desempenho - Variação 2004-2008}

\begin{tabular}{|c|c|c|c|c|c|c|c|c|c|c|c|c|c|c|c|c|}
\hline Cidade & $\begin{array}{l}\text { Tur } \\
\text { NVr }\end{array}$ & $\begin{array}{l}\text { Tur } \\
\text { IVr }\end{array}$ & $\begin{array}{c}\operatorname{RecN} \\
\mathbf{V r}\end{array}$ & $\underset{\mathbf{r}}{\operatorname{RecIV}}$ & \begin{tabular}{|c|} 
PerH \\
Vr
\end{tabular} & $\begin{array}{c}\text { PerNV } \\
\mathbf{r}\end{array}$ & $\begin{array}{l}\text { Per } \\
\text { IVr }\end{array}$ & $\begin{array}{c}\text { GstN } \\
\mathbf{V r}\end{array}$ & $\begin{array}{l}\text { Gst } \\
\text { IVr }\end{array}$ & $\begin{array}{c}\text { MeiH } \\
\text { Vr }\end{array}$ & InTt & $\operatorname{InTr}$ & STot & Sv45 & STur & ST45 \\
\hline Balneário Camboriú & $-10,16$ & $-15,17$ & 122,66 & 131,67 & $-22,31$ & $-13,73$ & 12,65 & 188,67 & 141,08 & 63,23 & 13 & 7 & 119 & 71 & 40 & 20 \\
\hline Bombinhas & $-17,85$ & 60,35 & 38,56 & 323,00 & 2,67 & 12,23 & 18,01 & 50,34 & 122,54 & $-29,86$ & 4 & 1 & 43 & 23 & 8 & 3 \\
\hline Itajaí & 26,82 & $-56,63$ & 146,12 & 100,56 & $-58,16$ & $-42,84$ & 20,43 & 243,53 & 257,29 & 123,49 & 12 & 4 & 96 & 31 & 39 & 7 \\
\hline Itapema & $-20,10$ & $-33,08$ & 46,52 & 10,63 & $-36,53$ & 0,66 & $-5,50$ & 61,52 & 75,01 & 112,50 & 4 & 1 & 51 & 39 & 29 & 24 \\
\hline Penha & 76,37 & $-65,17$ & 172,47 & $-7,02$ & $-35,90$ & 5,89 & $-5,98$ & 45,94 & 193,65 & $-27,35$ & 5 & 2 & 62 & 34 & 23 & 10 \\
\hline Porto Belo & 82,70 & $-94,00$ & 367,25 & $-92,62$ & $-9,75$ & $-7,96$ & $-23,08$ & 179,04 & 64,82 & 22,93 & 5 & 1 & 43 & 30 & 6 & 6 \\
\hline Média & 22,96 & $-33,95$ & 148,93 & 77,70 & $-26,66$ & $-7,62$ & 2,76 & 128,17 & 142,40 & 44,16 & 7 & 2,67 & 74,2 & 39,6 & 27,8 & 12,8 \\
\hline S & 47,017 & 53,555 & 119,65 & 144,42 & 21,636 & 19,612 & 17,059 & 85,812 & 73,189 & 66,889 & 3,898 & 2,422 & 32,182 & 18,487 & 13,141 & 8,871 \\
\hline
\end{tabular}

Nota. TurNVr: Número total de turistas nacionais; TurIVr: Número total de turistas internacionais; RecNVr: Receita total do turismo nacional (US\$); RecIVr: Receita total do turismo internacional (US\$); PerHVr: Pernoites hotelaria geral; PerNVr: Permanência turista nacional (dias); PerIVr: Permanência turista internacional (dias); GstNVr: Gastos turista nacional/dia (US\$); GstIVr: Gastos turista nacional/dia (US\$); InTt: Número total de instituições; InTr: Número total de instituições de turismo; STur: Número total de serviços prestados por instituições de turismo; MeiHVr: Hospedagem hotelaria (\%); STot: Número total de serviços prestados; Sv45: Número total de serviços prestados com ênfase (escala 4 e 5); ST45: Número total de serviços prestados por instituições de turismo com ênfase (valores 4 e 5 na escala). Fonte: elaborado pelos autores baseado em Secretaria de Estado de Turismo, Cultura e Esporte; SANTUR - Santa Catarina Turismo S/A; Diretoria de Planejamento e Desenvolvimento Turístico (2006). Pesquisa mercadológica estudo da demanda turística - Estado de Santa Catarina - Sinopse comparativa 2004,2005 e $2006 . \quad$ Recuperado de http://www.santur.sc.gov.br/images/stories/estatisticas/Demanda2006/si_2006_santa_catarina.pdf; Secretaria de Estado de Turismo, Cultura e Esporte; SANTUR - Santa Catarina Turismo S/A; Diretoria de Planejamento e Desenvolvimento Turístico (2008). Pesquisa mercadológica estudo da demanda turística - Estado de Santa Catarina - Sinopse comparativa 2006, 2007 e 2008 janeiro/fevereiro. Recuperado de http://www.santur.sc.gov.br/images/stories/estatisticas/Demanda2008/estado\%202008-1.pdf 
Merece destaque também o crescimento do uso da hotelaria em Balneário Camboriú em detrimento, em parte, do aluguel de casas. Nesse indicador, a maioria das cidades apresentou variações positivas maiores no uso da hotelaria em relação ao uso de aluguel. Apesar de estar fora do escopo deste trabalho, chamou a atenção que o motivador do turismo natureza variou negativamente em todas as cidades, à exceção de Itapema. Complementarmente, o atrativo história e cultura variou positivamente em todas as cidades e de forma significativa.

A Tabela 5 mostra o resultado das correlações significativas (Pearson) entre as variáveis de desempenho, as instituições e seus serviços. Apesar de não se poder afirmar a causalidade entre as variáveis, há certa lógica entre algumas correlações, como no caso da variação no número de turistas nacionais e a variação na receita advinda do turismo nacional. Também parece que os turistas nacionais e os internacionais concordam sobre a menor permanência na maioria dos destinos estudados.

Tabela 5

Correlação de Pearson para Variáveis de Desempenho, Instituições e Serviços

\begin{tabular}{|c|c|c|c|c|c|c|c|}
\hline & TurNVr & PerNVr & GstNV & InTt & $\operatorname{InTr}$ & STot & Sv45 \\
\hline $\operatorname{Rec} \mathrm{NVr}$ & $\begin{array}{l}, 867^{*} \\
, 015\end{array}$ & & & & & & \\
\hline PerIV & & $\begin{array}{l}, 733^{*} \\
, 039\end{array}$ & & & & & \\
\hline $\operatorname{InTr}$ & & & $\begin{array}{l}, \mathbf{7 8 8}^{*} \\
, \mathbf{0 3 2}\end{array}$ & $\begin{array}{c}, 692^{* *} \\
, 070\end{array}$ & & & \\
\hline STot & & & & & $\begin{array}{l}, 815^{*} \\
, 029\end{array}$ & & \\
\hline STur & & & $\begin{array}{l}, \mathbf{7 3 3}^{*} \\
, \mathbf{0 3 9}\end{array}$ & & $\begin{array}{l}, 788^{*} \\
, 032\end{array}$ & $\begin{array}{l}, 828^{*} \\
, 022\end{array}$ & $\begin{array}{c}, 600^{* *} \\
, 091\end{array}$ \\
\hline ST45 & & & & & & & $\begin{array}{l}, 867^{*} \\
, 015 \\
\end{array}$ \\
\hline
\end{tabular}

Nota. TurNVr: Número total de turistas nacionais; PerNVr: Permanência turista nacional (dias); GstNVr: Gastos turista nacional/dia; InTt: Número total de instituições; InTr: Número total de instituições de turismo; TurIVr: Número total de turistas internacionais; STot: Número total de serviços prestados; Sv45: Número total de serviços prestados com ênfase (escala 4 e 5); RecNVr: Receita total do turismo nacional (US\$); STur: Número total de serviços prestados por instituições de turismo; ST45: Número total de serviços prestados por instituições de turismo com ênfase (valores 4 e 5 na escala).Para esse estudo, assumiram-se duas possibilidades de significância: *p<0,05;** $p<0,10$, em função do número de casos ser pequeno. Esse procedimento foi adotado anterior por Martínez-Fernández, M. T. (2001). El modelo explicativo de la competitividad de la empresa en los distritos industriales: el efecto de los recursos compartidos (p. 293). (Tesis Doctoral). Universitat Jaume I, Castellón, España.

Quanto às instituições e seus serviços, percebe-se uma correlação positiva e significativa entre os gastos dos turistas nacionais e o número de instituições ligadas ao turismo, e outra ligada aos serviços turísticos totais. Mesmo sem que se possa apontar causalidade, essa correlação une, por um lado, as instituições e seus serviços e, por outro, um indicador de desempenho geral. A correlação entre instituições totais e aquelas ligadas ao turismo já era esperada. E a correlação entre as instituições de turismo, os serviços totais e os serviços turísticos também era esperada. Pelas características do produto/serviço turístico, as organizações públicas locais e regionais se veem obrigadas a estabelecer um conjunto de equipamentos turísticos e infraestrutura com vistas a atrair maior demanda turística para o destino, como indicam Beerli e Martin (2004 como citado em Shih, 2006). Ou seja, existe relação entre os serviços prestados e a competitividade do destino, e é o que se 
encontrou nesta pesquisa. Contudo, essa relação não foi tão ampla quanto se esperaria, talvez por que haja problemas em relação à diversidade dos serviços, como já foi apontado.

Modelos com características mais sistêmicas de avaliação de competitividade, como de Esser et al. (1994) e também de Dwyer e Kim (2003), evidenciam a dificuldade de se isolar determinados fatores para se poder indicar seu efeito individual. Ou seja, a competitividade de uma empresa ou, como nesse caso, de uma destinação, depende de vários fatores. Dwyer e Kim (2003) destacam, em seu modelo, que a administração da destinação, que envolve setor público e privado, exerce um papel importante, na medida em que é capaz de gerenciar os demais recursos da destinação, como aqueles herdados (natureza, cultura história etc.), e aqueles criados (infraestrutura hoteleira, meios de transporte etc.).

Esperava-se que o número de instituições e seus serviços fosse capazes de impactar em diversos indicadores. De certa forma, isso pode comprometer a confiança das empresas locais nas instituições, pois, como mostraram Nunkoo e Ramkissoon (2012), a ausência de resultados implica em que se diminua a confiança nessas instituições. Talvez o fato de as relações serem dinâmicas e se alterarem com o tempo, inclusive com o ingresso de novos atores, como apontaram Pavlovich (2003) e Wong et al. (2011), abra a possibilidade de se alterar o quadro e fazer como que as instituições passem a produzir maior impacto na competitividade do destino.

Como destacou André (2004), o êxito da gestão de uma destinação turística, neste caso traduzida em variações positivas nos indicadores de desempenho, pressupõe diálogo entre os agentes, a fim de que se trate o destino de forma integral. É possível que uma das razões para essa variação negativa e também para o reduzido número de correlações se deva à baixa interação entre as instituições das destinações, o que pode levar a dificuldades em termos de custo da própria gestão, e assim, comprometer a construção de cooperação intrarrede, como assinalaram Castro et al. (2011), ou mesmo interesses conflitantes, como escreveram Soares et al. (2011). Note-se que a interação maior interinstitucional, como mostrou Bonet (2004), pode trazer um alto desempenho em termos de demanda turística, além de auxiliar as empresas no processo de inovação de produtos e serviços, como mostraram Doloreux e Mattson (2008). Caberia uma reflexão acerca da instituição que parece exercer a governança local: a AMFRI, pois quando a rede não gera resultados, criam-se dificuldades à cooperação (Castro, Bulgacov, \& Hoffmann, 2011).

\section{Conclusão}

Este trabalho teve como objetivo avaliar as instituições de suporte à atividade turística em destinações turísticas na região do litoral norte de Santa Catarina. Pode-se perceber que há variabilidade de instituições na região, mas que isso não se reflete necessariamente em diversidade de serviços. Ou seja, há serviços, como as assessorias, que são largamente oferecidos, enquanto outros, como ações comerciais ou ações ligadas à sustentabilidade ambiental, recebem pouca ênfase no seu conjunto. Nota-se que os serviços não são os mesmos em todas as cidades e que, aquelas que possuem maior número de instituições, também o possuem em serviços. Também se conclui que, apesar de haver muitas instituições ligadas ao turismo, pouco mais da metade delas realmente possui o turismo no seu escopo. Isso até mesmo é reconhecido por elas. Outra conclusão: nas cidades, algumas instituições podem ser consideradas prevalentes, pois sua presença pode ser verificada em todas as localidades pesquisadas. Excluindo-se a SETUR, essas instituições são congregações de empresários, para fins específicos, ligados ao comércio e/ou manufatura de produtos. Ao que parece, os empresários, nessas cidades, começam a se organizar, constituindo CDL e ACI. Para o turismo, sua representação nesses fóruns pode ser menor, pois sua natureza ligada aos serviços não necessariamente é contemplada nesses organismos. Então, conclui-se que existem as redes nas aglomerações, que são do tipo interorganizacional, e que o papel das instituições públicas em tais redes locais é relevante, até mesmo para continuidade da atividade turística. Neste estudo também se 
conclui que as instituições, em função dos serviços que prestam, constituem-se como recursos estratégicos, que não são uniformes em cada cidade.

Além disso, para promover a competitividade de uma destinação turística, é preciso entender seus recursos e ter uma visão multinível dessa destinação (Dwyer \& Kim, 2003; Esser, Hillebrand, Messner, \& Meyer-Stamer, 1994). Como se trata de destino de sol e praia, parece importante salientar que as ações de sustentabilidade ambiental deveriam estar vinculadas à atividade turística ou, ao menos, ser uma das preocupações dessas instituições. Nota-se que, naquelas cidades onde há instituições próprias para o tema, ele é tratado de maneira seccionada e não sistêmica, como recomenda a literatura (Dwyer \& Kim, 2003). Assim, a destruição da natureza local significa o fim do próprio atrativo e da destinação em si, e essa é uma ameaça à constituição da própria rede.

Outro aspecto que chama a atenção é que as cidades são muito próximas e algumas delas, como Balneário Camboriú, Bombinhas, Itapema e Porto Belo têm no turismo um dos alicerces de sua economia. Essas quatro cidades, em particular, fazem divisas entre si, o que poderia justificar a ação mais enfática de instituições regionais como a AMFRI e, também, a própria Secretaria Regional. Elas são instituições formais, e, como salientou Kwasnicka (2006), a formalização pode ser importante para algumas redes. Talvez elas possam ser o ambiente onde haverá trocas maiores entre instituições e empresas, tal como foi observado em outros lugares (Hoffmann et al., 2011).

Nesse trabalho, conclui-se ainda que as instituições presentes podem ser recursos competitivos das destinações estudadas, mas não se pode assegurar que eles gerem vantagem competitiva a essas destinações. Como recursos de acesso, estariam disponíveis para todas as empresas. Assim, é possível que haja empresas que estejam se beneficiando da presença dessas instituições e de seus serviços mais que outras, como já foi apontado em outros estudos (Hoffmann, 2002). Mas como a unidade de análise é a destinação como um todo, esse tipo de ganho não foi verificado.

O que ainda está em aberto é saber o quanto essas instituições e seus serviços impactam no desempenho da destinação. Uma pista sobre o tema foi dada ao se constatar relação positiva entre os gastos dos turistas nacionais e o número de instituições turísticas nas cidades. Talvez suas ações coordenadas tragam um turista com maior poder aquisitivo, mesmo porque, como foi mostrado, a variação no número de turistas foi negativa.

Este estudo possui algumas limitações. A primeira diz respeito ao fato de ter-se entrevistado apenas uma pessoa de cada instituição, o que pode significar certo viés de resposta. Sempre se buscou aplicar o questionário à pessoa mais qualificada, mas, ao final, a indicação da instituição foi acatada pelos pesquisadores. Considera-se outra limitação a indisponibilidade de dados mais atualizados sobre o turismo local. Por exemplo, no ano de 2009, entre as sete cidades pesquisadas, somente três possuíam dados de demanda e, ainda assim, com variáveis distintas daquelas de 2004. Assume-se que a realidade pode ter se alterado, principalmente porque em 2009 novas gestões assumiram as prefeituras nas regiões e, como foi visto, o poder público local é um dos atores mais importantes. $\mathrm{O}$ volume de dados não permite que se apresentem todas as possibilidades de análise nesse trabalho. Também cabe trazer à discussão, uma vez mais, o modelo de Dwyer e Kim (2003), que explica a competitividade de uma destinação através de vários recursos competitivos, da gestão da destinação e através dos fatores situacionais e das condições de demanda. É possível que esses fatores tenham influenciado nos resultados das destinações que são mais sensíveis, pois se trata de dados agregados e, dessa forma, podem ter capturado melhor esses impactos negativos do que eventualmente a avaliação de empresas isoladas. Futuras pesquisas podem ser feitas em outras regiões, com o objetivo de comparar as realidades e verificar se existe um efeito localidade no papel das instituições de suporte à atividade turística. 


\section{Agradecimentos}

Os autores agradecem ao CNPq pelo apoio material para a realização desta pesquisa através do edital Universal; aos Revisores Anônimos e ao Editor da RAC por sua imprescindível colaboração no aprimoramento deste artigo.

\section{Referências}

André, M. (2004). Políticas locales de dinamización turística y grandes atractivos culturales: el caso de figures. In J. F. Sentias (Coord.), Casos de turismo cultural: de la planificación estratégica a la gestión del producto (Cap.6, pp. 157-182). Barcelona: Ariel.

Andrighi, F. F., \& Hoffmann, V. E. (2010). Redes e cooperação na destinação turística de Urubici/SC. Turismo em Análise, 21(1), 149-164.

Andrighi, F. F., Hoffmann, V. E., \& Andrade, M. A. R. (2011). Análise da produção científica no campo de estudo das redes em periódicos nacionais e internacionais. Revista de Administração e Inovação, 8(2), 29-54. doi: 10.5773/rai.v8i2.530

Asheim, B. T., \& Isaksen, A. (2002). Regional innovation systems: the integration of local 'sticky' and global 'ubiquitous' knowledge. Journal of Technology Transfer, 27(1). 77-86. doi: 10.1023/a:1013100704794

Baggio, R., Scott, N., \& Cooper, C. (2010). Network science a review focused on tourism. Annals of Tourism Research, 37(3), 802-827. doi: 10.1016/j.annals.2010.02.008

Baldi, M., Milano, M., \& Vieira, F. (2006). Calçado do vale: imersão social e redes interorganizacionais. Revista de Administração de Empresas, 46(3), 16-27. doi: 10.1590/S0034-75902006000300003

Balestrin, A., Verschoore, J. R., \& Reyes, E., Jr. (2010). O campo de estudo sobre redes de cooperação interorganizacional no Brasil. Revista de Administração Contemporânea, 14(3), 458-477. Recuperado de http://www.scielo.br/pdf/rac/v14n3/v14n3a05.pdf. doi: $10.1590 / \mathrm{S} 1415-65552010000300005$

Barney, J. B. (1991). Firm resources and sustained competitive advantage. Journal of Management, 17(1), 99-120. doi: 10.1177/014920639101700108

Becattini, G. (1979). Dal settore industriale al distretto industriale. Alcune considerazione sull'unitá di indagine in economia industriale. Revista di Economia e Política Industriale, 1(1), 1-8.

Bellandi M., \& Caloffi, A. (2008). District internationalisation and trans-local development. Entrepreneurship \& Regional Development, 20(6), 517-532. doi: 10.1080/08985620802462108

Benton, L. (1993). La emergencia de los distritos industriales en España. In F. Pyke \& W. Sergenberger (Eds.), Los DI y las PYMEs: DI y regeneración económica local [Colección Economía y Sociología del Trabajo]. (Cap. 3, pp. 81-128). Madrid: MSSS.

Beritelli, P. (2011). Cooperation among prominent actors in a tourist destination. Annals of Tourism Research, 38(2), 607-629. doi: 10.1016/j.annals.2010.11.015

Bonet, L. (2004). La estrategia de turisme de Barcelona, un consorcio público-privado de éxito. In J. F. Sentias (Coords.), Casos de turismo cultural: de la planificación estratégica a la gestión del producto (Cap. 9, pp. 235-260). Barcelona: Ariel. 
Brusco, S. (1982). The emilian model: productive decentralization and social integration. Cambridge Journal of Economics, 6, 167-184.

Brusco, S. (1993). Pequeñas empresas y prestación de servicios reales. In F. Pyke \& W. Sergenberger (Eds.), Los DI y las PYMEs: DI y regeneración económica local [Colección Economía y Sociología del Trabajo]. (Cap. 6, pp. 235-254). Madrid: MSSS.

Castro, M., Bulgacov, S., \& Hoffmann, V. E. (2011). Relacionamentos interorganizacionais e resultados: estudo em uma rede de cooperação horizontal da região central do Paraná. Revistra de Administração Contemporânea, 15(1), 25-46. Recuperado de http://www.scielo.br/pdf/rac/v15n1/v15n1a03.pdf. doi: 10.1590/S1415-65552011000100003

Czajkowski, A., \& Cunha, S. K. (2010). Organização e coordenação da rede de cooperação em aglomerados de turismo rural. Turismo Visão e Ação, 12(1), 92-113.

Dei Ottati, G. (1987). Il mercato comunitario. In G. Becattini (Ed.), Mercato i forze locali: il distretto industriale (pp. 117-142). Bologna: Il Mulino.

Doloreux, D., \& Mattson, H. (2008). To what extent do sectors "socialize" innovation differently? Mapping cooperative linkages in knowledge-intesive industries in the Ottawa Region. Industry Innovation, 15(4), 351-370. doi: 10.1080/13662710802239463

Donaire, D., Silva, M. P., \& Gaspar, M. A. (2009). A rede de negócios do turismo: um estudo sobre suas características e implicações estratégicas. Turismo Visão e Ação, 11(1), 112-134.

Dwyer, L., \& Kim, C. (2003). Destination competitiveness: determinants and indicators. Current Issues in Tourism, 6(5), 369-416. doi: 10.1080/13683500308667962

Esser, K., Hillebrand, W., Messner, D., \& Meyer-Stamer, J. (1994). Competitividad sistémica: competitividad internacional de las empresas y políticas requeridas (Estudios e Informes 11). Berlín: Instituto Alemán de Desarrollo.

Franco, M. J. B. (2007). Tipologia de processos de cooperação empresarial: uma investigação empírica sobre o caso português. Revista de Administração Contemporânea, 11(3), 149-176. doi: 10.1590/S1415-65552007000300008

Freeman, S., Edwards, R., \& Schroder, B. (2006). How smaller born-global firms use networks and alliances to overcome constraints to rapid internalization. Journal of International Marketing. 14(3), 33-63. doi: 10.1509/jimk.14.3.33

Haugland, S. A., Grønseth, H. N. B. O., \& Aarstad, J. (2011). Development of tourism destinations: an integrated multilevel perspective. Annals of Tourism Research, 38(1), 268-290. doi: 10.1016/j.annals.2010.08.008

Hocayen-da-Silva, A. J., \& Teixeira, R. M. (2009). Análise dos relacionamentos interoganizacionais em empresas do setor hoteleiro de Curitiba: estudo comparativo de casos. Revista Brasileira de Pesquisa em Turismo, 3(2), 24-48.

Hoffmann, V. E. (2002). Los factores competitivos de la empresa a partir de la perspectiva de los distritos industriales. Un estudio de la industria de cerámica de revestimiento de Brasil (Tesis Doctoral). Unversidad de Zaragoza, Zaragoza, España.

Hoffmann, V. E., Bandeira-de-Melo, R., \& Molina-Morales, F. X. (2011). Innovation and knowledge transfer in clustered interorganizational networks in Brazil. Latin America Business Review, 12(3), 143-163. doi: 10.1080/10978526.2011.614168

Kwasnicka, E. L. (2006). Governança gestora na rede de negócios: um estudo comparativo. Revista Brasileira de Gestão de Negócios, 8(21), 33-42. 
Magalhães, J. M., Daubt, C. G., \& Phonlor, P. R. (2009). Vantagens proporcionadas às pequenas e médias empresas por meio da união em redes de cooperação no contexto do venture capital. Revista de Administração Contemporânea, 13(4), 583-603. Recuperado de http://www.scielo.br/pdf/rac/v13n4/a05v13n4.pdf. doi: 10.1590/S1415-65552009000400005

Malmberg, A., \& Power, D. (2005). (How) Do (firms in) clusters create knowledge? Industry and Innovation, 12(4), 409-431. doi: 10.1080/13662710500381583

Marshall, A. (1925). Principles of economics (8ve ed.). London: Macmillan.

Martínez-Fernández, M. T. (2001). El modelo explicativo de la competitividad de la empresa en los distritos industriales: el efecto de los recursos compartidos (Tesis Doctoral). Universitat Jaume I, Castellón, España.

Mesquita, L. F., \& Lazzarini, S. G. (2010). Horizon and vertical relationships in developing economies: implicantions for smee access to global markets. In D. B. Audretsch, G. B. Dagnino, R. Faraci, \& R. E. Hoskisson, (Eds.), New frontiers in entrepreneurship. Recognizing, seizing, and executing opportunities [Series: International Studies in Entrepreneurship]. (Vol. 26, Cap. 3, pp. 31-66). London: Springer.

Molina-Morales, X., López-Navarro, M. A., \& Guia-Julve, J. (2001, May). Social capital in territorial agglomerations of firms: opportunities and restraints. Proceedings of Conference of the European Group for organizational studies, Paris, France, 17.

Nunkoo, R., \& Ramkissoon, H. (2012). Power, trust, social exchange and community support. Annals of Tourism Research, 39(2), 997-1023. doi: 10.1016/j.annals.2011.11.017

Paniccia, I. (1998). One, hundred, thousands of industrial districts. Organizational variety in local networks of small and medium- sized enterprises. Organizational Studies, 19(4), 667-699. doi: $10.1177 / 017084069801900406$

Parrilli, M. D., \& Sacchetti, S. (2008). Linking learning with governance in clusters and networks: key issues for analysis and policy. Entrepreneurship and Regional Development, 20(4), 387408. doi: 10.1080/08985620801886463

Pavlovich, K. (2003). The evolution and transformation of a tourism destination network: the Waitomo Caves, New Zealand. Tourism Management, 24(2), 203-216. doi: 10.1016/S02615177(02)00056-0

Richardson, R. J. (1985). Pesquisa social: métodos e técnicas. São Paulo: Atlas.

Rodrigues, A., \& Rodrigues, A. (2009). Turismo e inovação em espaços rurais: estudo de caso da rede europeia de turismo de aldeia. Turismo em Análise, 20(1), 35-47.

Rodrigues, L. C., Maccari, E. A., \& Riscarolli, V. (2007). Arquitetura e coopetição em redes interorganizacionais. JISTEM J.Inf.Syst. Technol. Manag, 4(2), 175-196.

Sacramento, P. M., Teixeira, R. M., \& Cerqueira, A. C. (2010). Redes de cooperação entre pequenas empresas do setor hoteleiro e a rede turística: um estudo de casos múltiplos em Aracaju, Sergipe. Revista OIT, 5(1), 1-16.

Secretaria de Estado de Planejamento e Desenvolvimento Econômico. (2009). Relatório de ação governamental - Sintese 2003-2009. Manaus, AM. Recuperado de http://www.seplan.am.gov.br/arquivos/download/arqeditor/relatorio_de_acao_governamental_2 009.pdf

Secretaria de Estado de Turismo, Cultura e Esporte; SANTUR - Santa Catarina Turismo S/A; Diretoria de Planejamento e Desenvolvimento Turístico (2006). Pesquisa mercadológica 
estudo da demanda turística - Estado de Santa Catarina - Sinopse comparativa 2004, 2005 e $2006 . \quad$ Recuperado de http://www.santur.sc.gov.br/images/stories/estatisticas/Demanda2006/si_2006_santa_catarina.p df

Secretaria de Estado de Turismo, Cultura e Esporte; SANTUR - Santa Catarina Turismo S/A; Diretoria de Planejamento e Desenvolvimento Turístico (2008). Pesquisa mercadológica estudo da demanda turística - Estado de Santa Catarina - Sinopse comparativa 2006, 2007 e 2008 janeirolfevereiro. Recuperado de http://www.santur.sc.gov.br/images/stories/estatisticas/Demanda2008/estado\%202008-1.pdf

Schmitz, H. (1993). Distritos industriales: modelo y realidad en Baden-Würtemberg. In F. Pyke \& W. Sergenberger (Eds.), Los DI y las PYMEs: DI y regeneración económica local [Colección Economía y Sociología del Trabajo]. (pp. 27-62). Madrid: MSSS.

Scott, N., Cooper, C., \& Baggio, R. (2008). Destination networks: four Australian cases. Annals of Tourism Research, 35(1), 169-188. doi: 10.1016/j.annals.2007.07.004

Shih, H-Y. (2006). Network characteristics of drive tourism destinations: an application of network analysis in tourism. Tourism Management, 27(5), 1029-1039. doi: 10.1016/j.tourman.2005.08.002

Soares, A. S., Castro, C. C., Brito, M. J., \& Alves, R. R. (2011). Benefícios competitivos e conflitos em rede horizontal do setor supermercadista. Revista Eletrônica de Administração, 17(2), 530559. doi: 10.1590/S1413-23112011000200009

Swan, J. A., \& Newell, S. (1995). The role of professional associations in technology diffusion. Organizational Studies, 16(5), 847-872. doi: 10.1177/017084069501600505

Trimarchi, M. (2004). Distritos culturales y desarrollo económico del territorio: la experiencia de los museos de Siena. In J. F. Sentias (Coord.), Casos de turismo cultural: de la planificación estratégica a la gestión del producto (Cap. 4, pp. 109-124). Barcelona: Ariel.

Verschoore, J. R., \& Balestrin, A. (2008). Fatores relevantes para o estabelecimento de redes de cooperação entre empresas do Rio Grande do Sul. Revista de Administração Contemporânea, 12(4), 1043-1069. doi: 10.1590/S1415-65552008000400008

Wernerfelt, B. (1984). A resource-based view of the firm. Strategic Management Journal, 5(2), 171180. doi: $10.1002 / \mathrm{smj} .4250050207$

Whittington, K. B., Owen-Smith, J., \& Powell, W. W. (2009). Networks, propinquity, and innovation in knowledge-intensive industries. Administrative Science Quarterly, 54(1), 90-122. doi: 10.2189/asqu.2009.54.1.90

Wong, E. P. Y., Mistilis, N, \& Dwyer, L. (2011). A framework for analyzing intergovernmental collaboration. The case of ASEAN tourism. Tourism Management, 32(2), 367-376. doi: 10.1016/j.tourman.2010.03.006

Zylberstajn, D., \& Farina, E. M. M. Q. (2010). Dinâmica de governança de redes: uma contribuição para o estudo de formas complexas. Revista Eletrônica de Administração, 16(1), 1-19. 